\title{
A survey of the use of depot neuroleptics in a whole region
}

\author{
A study on behalf of the Research Committee, Royal College of Psychiatrists
}

\author{
John CRAMmer, Reader Emeritus, Institute of Psychiatry, London; and \\ Donald ECCLESTON, Professor of Psychiatry at Newcastle
}

Fluphenazine enanthate ('Moditen') for injection at monthly or more frequent intervals for the treatment of schizophrenia was introduced about 20 years ago, and shown in controlled trials to be beneficial in preventing relapse (Hirsch et al, 1973). Such depot treatment has become widespread as a part of the care of patients in the community. Four products are now in common use: fluphenazine decanoate ('Modecate'); flupenthixol decanoate ('Depixol'); zuclopenthixol decanoate ('Clopixol'); and haloperidol decanoate ('Haldol decanoate'): we will refer to them by trade names for brevity. Some use is also being made of pipothiazine palmitate ('Piportil') and fluspirilene ('Redeptin').

Many people out of hospital are receiving one of these drugs over a period of years, and the Research Committee thought it reasonable to enquire how these cases are monitored, how far the treatment continues beneficial or presents health problems in the long-term, what clinical conditions it is now being used for, and on what scale? It was decided to make a pilot study in one population using postal questionnaires to try to answer some of these questions, which may be regarded as a form of medical audit. The results of this pilot would be very tentative, but would, it was hoped, guide any fuller and more definitive enquiry later. With the advice of Drs Sheila Mann, John Pippard and Pamela Taylor, the computer aid of Dr A. Johnson (MRC Biostatistics Unit, Cambridge), and the administrative and secretarial help throughout of Miss Jane Boyce of the College staff, we sent questions to all the general practitioners and psychiatrists in the Northern Regional Health Authority (NHS) Area based on Newcastle upon Tyne. About 3.085 million people live in this area, with 1,717 GPs and 219 psychiatrists of various ranks in the NHS. There are about 3,000 beds for psychiatric illness and a similar number of beds for mental handicap, divided among a number of hospitals in the nine geographical subdivisions of the area. We believe it is the first time an attempt has been made to examine the use of a psychotropic drug in a whole population. The fact that the drugs are all on prescription, and every dose must be given by a nurse or doctor facilitates study.

\section{The study}

The names and addresses of all doctors in the area were obtained from the nine Family Practitioner Committees, the Area Health Authority, and College lists. Each doctor was sent two letters with post-paid envelopes for reply. The first letter contained a request from Professor Eccleston, personally known to many of them, asking for their help, and a questionnaire in two parts: A, asking about the individual's daily work and rank and whether he/she had ever had a patient on a depot drug (if not, the answer 'NO' posted back was sufficient); and B, (for those who admitted experience) asking who prescribed initially and now, who gave the injections, what drugs were favoured, what was done about follow-up and failure to attend.

Two weeks later a second letter was sent, so that the doctor and his assistants could list every depot patient they dealt with in a 28-day census month (March 1987). It contained form C, on which to enter every patient newly started on depot treatment during 28 days, and form $D$ on which to list every case stopping treatment for any reason in the same time, and also all cases continuing with one or more injections in the month. To avoid duplicating entries of the same patient yet preserve confidentiality, the forms asked for date of birth in each case and the first letter of the first name, plus the first three letters of the family name. Drug, dose, frequency and duration of treatment so far, concurrent oral medication and a diagnosis were to be given. The lists were often compiled with the help of ward nurses, practice nurses and community psychiatric nurses, sometimes several working with one medical respondent. All replies were sent to Cambridge for computer analysis and subsequently examined by us. Owing to lack of funds and manpower no further communication was made to those who failed to reply to our second letter 
(with census forms) to encourage them to do so. We were very grateful to those doctors who did reply. Copies of our questionnaire ABCD are filed in the College library.

\section{Findings}

1. Replies Out of 219 doctors in psychiatric practice, $128(58 \%)$ replied. However, the 54 senior house officers yielded only 10 replies, some pointing out they were too new and inexperienced to answer usefully. Of 34 registrars and 23 senior registrars, $40 \%$ replied, many indicating that they prescribed and even initiated depot treatment, though this was mostly done by consultants in general psychiatry (109 [65\%] replied). Understandably only three of the 30 consultants in child psychiatry and mental handicap used the drugs. The two-thirds of consultants who sent information probably represents a fair coverage.

Out of 1,717 GPs, $687(40 \%)$ replied. Since many work in partnerships of two to seven or even more doctors, where one partner may answer for all, the response rate for practices has also been calculated (see Table I) and in some areas is much better, 63$78 \%$. This may depend on the proportion of singlehanded practices in an area, since these answered less often, e.g. about $25 \%$ single handed in Cleveland, but $40 \%$ or so in Sunderland, and less than one-third of these doctors replied, whereas over two-thirds of the group practices in both cases did so. Table I also shows that up to about eight times more doctors replied than were actually involved in a case. There are many reasons why replies might fail; too busy, confused records, no experience of the treatment, against enquiries, off sick, moved address. The effect of a $40 \%$ overall response may be to understate the figures and sometimes bias them. Nevertheless they are of such magnitude as unavoidably to make certain points, some of which compare well with findings by other workers.

2. Patients The census reported 2,018 patients; of whom 80 began treatment with depot in the census month (initiated by GPs in 11) and 55 stopped treatment then. Of the 1,883 continuing, almost a quarter (440) were under GP care, while 1,140 were outpatients of psychiatrists, 244 were in-patients (and 59 were unlocated).

Stopping in almost half the cases meant failing to attend for injection, but a further quarter refused to go on. In only a quarter was the stop within 12 months of starting; almost half had been under such treatment for more than two years.

A quarter of the 80 who started were aged 20-29, and another 14 aged 40-49. But nearly half were over 60 (17 patients aged 70 plus began treatment). Of those already continuing treatment, three-quarters of them already into their second year or longer, $25 \%$ of those under psychiatrists were aged 60 plus; in fact there were 93 cases reported in the 70-79 decade, 35 in the 80-90, and two over 90 . Clearly depot drugs are important in geriatic treatment, and restless dementia was stated as one indication (see also Raskind \& Risse, 1986). The present enquiry also found nine patients aged 10-19 on depot. Apart from schizophrenia, the drugs were in use in recurrent affective disorder (especially for hypomania) and in a few cases in what were regarded as neurotic or personality disorders. In his survey of 109 patients attending in a district service in London, Holloway (1988) noted nine neurosis/personality cases treated with antipsychotics.

3. Drugs Modecate and Depixol were principally. used, with the suggestion that the choice of drug

TABLE I

Geographical distribution of GPs, practices and GP treated patients

\begin{tabular}{|c|c|c|c|c|c|c|c|}
\hline $\begin{array}{l}\text { Area and } \\
\text { population }\end{array}$ & $\begin{array}{c}\text { Total } \\
\text { doctors }\end{array}$ & $\begin{array}{c}\text { Doctors } \\
\text { replying } \\
\text { (\%tot) }\end{array}$ & $\begin{array}{l}\text { Practices } \\
\text { replying } \\
\text { (\%tot })\end{array}$ & $\begin{array}{l}\text { Number of } \\
\text { doctors (D) } \\
\text { with patients }\end{array}$ & $\begin{array}{c}\text { Number of } \\
\text { patients }(P)\end{array}$ & $P / D$ & $\begin{array}{l}G P-P \text { per } \\
\text { population }\end{array}$ \\
\hline Cleveland $(684,000)$ & 307 & $115(38 \%)$ & $101(63 \%)$ & 15 & 58 & 3.86 & 1 per 11,800 \\
\hline Cumbria $(484,400)$ & 270 & $116(43 \%)$ & - & 33 & 123 & 3.72 & 1 per 3,900 \\
\hline Durham $(476,800)$ & 301 & $102(33 \%)$ & - & 19 & 86 & 4.5 & 1 per 5,500 \\
\hline Northumberland $(300,600)$ & 162 & $76(47 \%)$ & $50(78 \%)$ & 27 & 77 & 2.85 & 1 per 3,900 \\
\hline Gateshead $(208,100)$ & 110 & $46(42 \%)$ & $33(72 \%$ & 8 & 20 & 2.5 & 1 per 10,000 \\
\hline Newcastle $(282,100)$ & 168 & $99(59 \%)$ & - & 10 & 28 & 2.8 & 1 per 10,000 \\
\hline N Tyneside $(193,200)$ & 101 & $31(30 \%)$ & $23(65 \%)$ & 4 & 16 & 4.0 & 1 per 12,000 \\
\hline S Tyneside $(157,600)$ & 72 & $29(40 \%)$ & $21(66 \%)$ & $\mathbf{0}$ & - & - & - \\
\hline Sunderland $(298,800)$ & 222 & $73(33 \%)$ & $100(45 \%)$ & 9 & 37 & 4.1 & 1 per 8,700 \\
\hline TOTAL & 1,713 & 687 & & 125 & 445 & & \\
\hline
\end{tabular}


might be influenced by age and diagnosis, as well, of course, as individual consultant's preference. Injections were mostly given on a two-week schedule, less often monthly, in a few cases weekly (one in eight of those on Clopixol, one in 20 of those on the other common drugs). Most patients received a dose at the lower end of the range quoted for each in the British National Formulary; but 24 cases were on doses beyond the top of the Modecate range and 21 above that for Haldol decanoate, supporting the opinion of some psychiatrists that a few patients may benefit from exceptionally high doses. There were also 65 patients on these two drugs in small quantity, below the BNF minimum, 167 below the Depixol minimum and 28 below the Clopixol minimum. One inevitably wonders whether the BNF recommended dose represents the true therapeutic course.

About half of all the reported cases were on antiparkinsonian medication, and in a quarter of the psychiatrists' cases and a third of those under GPs, the injections were supplemented with oral psychotropics. One in three of the GP cases were having oral neuroleptics such as chlopromazine or thioridazine, the others antidepressants or benzodiazepines. Surveys of patients under hospital psychiatrists in London (Holloway, 1988), Scotland (McCreadie et $a l, 1984)$, and Birmingham (Edwards \& Kumar, 1984) have produced similar figures for supplementary medication.

4. Follow-up Asked about this, about one-third of both GPs and psychiatrists who replied said they saw their depot patients regularly, half monthly, half quarterly. The other two thirds said review was irregular or were silent on the subject. Some of the psychiatrists had such big lists of depot cases that regular contact would be very time-consuming; 35 specialists had more than 10 depot patients each currently on their lists, but six had anything from 70 to 159 . It is really a minority of psychiatrists who are carrying the out-patient load, in some geographical areas two or three, in others five or six. It is probable that such follow-up as there is depends heavily on the community psychiatric nurses, who were not directly questioned in this survey. Of the 125 GPs reporting cases in the census month, one-third had only one case each, and another half had two to six cases on their books. Some of the big group practices had even more. Again the impression is that only a small minority of GPs are dealing with these cases, even though they care for a quarter of the total identified in the community.

\section{Comment}

The census revealed about 2,000 people on depot injection treatment in a population of 3 million, or about one in 1,500. This seems a very possible figure and, if representative, implies about 32,000 in England and Wales as a whole, about a quarter of them over 60 years old. In other words, the scale is such that depot treatment is a significant factor in the public health, and we need to know more about its usefulness over years in psychiatry, and its influences (if any) on physical morbidity and mortality. There must at present be some doubt about the adequacy of follow-up care in all cases, and there need to be clear lines when a psychiatric case should revert to the GP, and how the responsibilities should lie. In the Table it appeared that the nine geographical areas differed threefold to the extent to which GPs had (or reported) cases (last column). But when the psychiatric out-patients in each area are taken into acount, the total cases per area are much more similar in relation to population, one in 1,300 to one in 2,000. GPs in the more rural areas, Cumbria and Northumberland, have proportionally more of the patients probably because of the difficulties of travel to hospital clinics.

Previous studies of the use of depot neuroleptics, in London, Oxford, Birmingham, Scotland and elsewhere have been on the in-patient and daypatient population of a single hospital, or limited in some other way, e.g. to those between the ages of 18-64. Ours reveals the importance of the elderly patient and of GP care, and has a difference of scale. The most relevant paper to our underlying purpose is that of Curson et al (1985) who studied a very few cases extremely carefully after seven years on a depot drug. These London patients had been part of the MRC trial (Hirsch et al, 1973) of the value of this drug treatment in preventing relapse in the short term. Now seven years later the 64 survivors were re-examined. Over half of them had had oral neuroleptic supplements at some time and 10 of them were so supplemented at the time of review. Although 11 had remained in complete remission, the others had had a total of 172 episodes of schizophrenic illness between them, and 40 of the patients had a total of 94 in-patient admissions, in spite of continued injection treatment and regular follow-up. Strikingly, 14 out of 62 were in a state of relapse at the time of the clinical review, and eight of these relapsers were unrecognised as such although attending a-maintenance clinic (three cases), a day centre (two cases), or a GP (three cases). A postal survey cannot answer questions about the clinical state of patients, the presence of mental symptoms and physical signs and variation in course over time, nor is it very helpful in judging social adjustment. This requires an extended formal routine examination by interviewers working to standards held in common. Curson et al (1985) have revealed many deficiencies in their small group: are these widespread? What would we find in our Northern 2,000? 


\section{Acknowledgements}

We are grateful to Messrs Squibb, Lundbeck, May \& Baker, and Janssen Pharmaceuticals for gifts towards our costs; to Professors Andrew Sims and Michael Gelder, Chairmen past and present of the Research Committee, for active support throughout; to Dr A. Johnson who was generous with his time and advice; also to the GPs, consultants and community nurses in the Northern Region, who filled in the responses.

\section{References}

Curson, D. A., Barnes, T. R. E., Bamber, R. W., Platt S. D., HiRSCH, S. R. \& DuFfY, J. C. (1985) Long term depot maintenance of chronic schizophrenic outpatients; the seven-year follow up of the MRC Fluphenazine/ placebo trial. British Journal of Psychiatry, 146, 464-480.

EDWARDS, S. \& KUMAR, V. (1984) A survey of prescribing of psychotropic drugs in a Birmingham psychiatric hospital. British Journal of Psychiatry, 145, 502-507.

Hirsch, S. R., GAIND, R., RoHDE, P. D., STEVENS, B. C. \& WING, J. K., (1973) Outpatient maintenance of chronic schizophrenic patients with long-acting fluphenazine: double blind placebo trial. British Medical Journal, 1, 633-637.

Holloway, F. (1988) Prescribing for the long-term mentally ill; a study of treatment practices. British Journal of Psychiatry, 152, 511-515.

MCCREAdie, R. G., Robinson, A. D. \& Wilson, A. O. A. (1984) The Scottish survey of chronic day-patients. British Journal of Psychiatry, 145, 626-630.

Raskind, M. A. \& Risse, S. C. (1986) Antipsychotic drugs and the elderly. Journal of Clinical Psychiatry, 146 (5 Supplement), 17-22.

\section{The College Library}

Once again, we are extremely grateful to members of the College who continue to donate copies of their current works to the Library. We wish, in particular, to thank Dr J. G. Howells for the collection of his works, as well as the following members who have so generously donated copies of their current works during the last six months:

Dr M. O. Aveline Group Therapy in Britain

Dr A. Bentovim Child Sexual Abuse within the Family: Assessment and Treatment

Professor H. Freeman Interaction between Mental and Physical Illness

Professor D. W. Goodwin Psychiatric Diagnosis, 4th ed; Alcohol and the Writer; Is Alcoholism Hereditary?

Dr R. A. Haig The Anatomy of Humor: Biopsychosocial \& Therapeutic Perspectives

Dr A. S. Henderson An Introduction to Social Psychiatry

Drs A. S. \& J. H. Henderson Etiology of Dementia of Alzheimer's Type

Dr P. D. Hill Adolescent Psychiatry

Dr J. G. Howells Modern Perspectives in Psychosocial Pathology, Vol 11

Dr M. Jones Growing Old-The Ultimate Freedom

Professor K. Jones Experience in Mental Health: Community Care \& Social Policy

Professors W. I. N. Kessell and H. J. Walton Alcoholism: A Reappraisal-Its Causes, Problems and Treatment

Professor H. G. Morgan Aids to Psychiatry

Dr R. L. Palmer Anorexia Nervosa: A Guide for Sufferers and Their Families
Dr C. M. Parkes Psychological Problems in General Practice

Professor A. C. P. Sims Anxiety in Clinical Practice

Dr D. A. Spencer YRPA - Fortieth Anniversary

Dr P. J. Tyrer The Psychopharmacology of Anxiety; Personality Disorders: Diagnosis, Management and Course

Dr D. Waxman Hartland's Medical and Dental Hypnosis, 3rded

Dr G. Wilkinson Depression: Family Doctor Guides (BMA)

Dr S. Wolff Childhood \& Human Nature: The Development of Personality

\section{Basic Sciences}

The Basic Sciences Reading List for trainees, produced by the Library, is now available from the College. Price $f 1$.

\section{Belgrave Square}

The Library has acquired a copy of an historical essay on Belgrave Square by the architectural historian W. Carey. The essay covers the history of the Square with details of number 17 and includes copies of maps of the area dating back to 1745 .

SUSAN FLOATE Librarian 